\title{
Control of Pd catalyst selectivity with mixed thiolate monolayers
}

\author{
Chih-Heng Lien and J. Will Medlin*
}

Department of Chemical and Biological Engineering, University of Colorado Boulder, Jennie Smoly Caruthers Biotechnology Building 596 UCB, Boulder, CO 80309-0596,

USA

\begin{abstract}
:
Metal catalysts coated with self-assembled monolayers have been found to exhibit improved performance in a number of reactions, but previous work has focused on deposition of uniform layers from a single precursor. In this study, we investigate how the use of variable-composition monolayers formed from mixtures of 1-adamantanethiol (AT) and 1-octadecanethiol (C18) can be used to control catalyst performance and provide insights into both monolayer ordering and surface reaction mechanisms. Benzyl alcohol hydrodeoxygenation to toluene was used as a probe reaction for these studies. The mixed monolayer composition was controlled by varying the proportion of $\mathrm{AT}$ to $\mathrm{C} 18$ in an ethanol solution used for deposition. For AT-modified catalysts, toluene selectivity was higher than for the uncoated catalyst. Increases in the $\mathrm{C} 18$ surface fraction $\left(\mathrm{y}_{\mathrm{C} 18}\right)$ in the monolayers resulted in further increases in toluene selectivity, with selectivity approaching 98\% near complete conversion at full $\mathrm{C} 18$ coverage. Infrared spectra collected after dosing CO or benzyl alcohol also indicated that increasing $\mathrm{y}_{\mathrm{C} 18}$ lowered the ratio of bridging and three-fold adsorption on high coordination sites compared to linear adsorption on low coordination sites. These results suggested that the mechanism for selectivity enhancement was at least partly due to selective poisoning of terrace sites and reduction of contiguous active sites. Whereas selectivity was observed to follow a continuous
\end{abstract}


increasing trend with increasing thiolate coverage, trends in reaction rates were more complex. A sharp $60 \%$ decrease in the rate of the undesired decarbonylation (DC) reaction was observed when $\mathrm{y}_{\mathrm{C} 18}$ was increased from zero to 0.15 . This sharp decrease at low $\mathrm{y}_{\mathrm{C} 18}$ was attributed to the filling in of defects in AT monolayers by $\mathrm{C} 18$. Control of mixed monolayer composition allowed for tuning of the catalyst performance such that the same rate of toluene production could match that over the uncoated catalyst, while the decarbonylation rate was decreased by an order of magnitude, providing an active, highly selective catalyst. Beyond catalyst design, these investigations demonstrate that catalyst evaluation can serve as a valuable tool for understanding monolayer organization. 


\section{Introduction}

Supported noble-metal nanoparticles are widely utilized in industry for production of a variety of valuable chemicals. In addition to high activity, these catalysts must have high selectivity to reduce feedstock waste, separation costs, and byproduct formation. Chemoselectivity is an especially important issue for the conversion of biomass to fuels and chemicals, where the multiple functional groups commonly present in biomass-derived oxygenates cause significant challenges in catalyst design[1-4].

Benzyl alcohol is one of the many biomass-derived intermediates produced during lignin degradation[5-8] and can be converted to various products through several reactions, such as decarbonylation (DC) to benzene, dehydrogenation (DH) to benzaldehyde, and hydrodeoxygenation (HDO) to toluene. More importantly, it is also a useful aromatic probe molecule that has been studied using an array of surface science techniques, so that there is a relatively good understanding of its surface reactivity on late transition metals such as $\mathrm{Pd}[9-13]$. One of the main reasons that the HDO mechanism can be understood in detail using surface science studies for benzyl alcohol is that the $\mathrm{C}-\mathrm{O}$ bond is relatively weak, allowing the deoxygenation process to be tracked in ultrahigh vacuum on model surfaces[10,14]. Thus, studies of methods to control HDO on supported metal catalysts can be compared directly to results from detailed surface-level investigations.

Similar to other biomass-derived oxygenates, benzyl alcohol HDO suffers from low selectivity because the reactant can adopt various adsorption configurations on noble metal surfaces and undergo reactions to a variety of products[10, 12, 13]. Among the products from benzyl alcohol, toluene has broad application as a chemicals precursor, fuel additive and solvent. Compared with toluene, benzene is far more toxic, environmentally unfriendly and carcinogenic. Therefore, design of catalysts for high selectivity to toluene without benzene production is worthy of investigation. More importantly, benzyl alcohol can serve as a model oxygenate for understanding mechanisms for promoting deoxygenation reactions over $\mathrm{C}-\mathrm{C}$ bond-breaking reactions.

Previous studies have identified several factors that influence benzyl alcohol oxidation selectivity in an aerobic environment, such as the nature of the 
support[15-18], the composition of bimetallic catalysts[18-26], and the size and shape of the metal nanoparticles[26-28]. By optimizing the catalyst and reaction environment, selectivity for benzyl alcohol dehydrogenation to benzaldehyde has been reported over 97\% with high turnover frequency. However, less attention has been paid to benzyl alcohol HDO to toluene.

One simple concept for controlling selectivity is via selective poisoning of surface sites that catalyze particular reactions[29-36]. Our previous studies have shown that modification of $\mathrm{Pd}(111)$ surfaces and $\mathrm{Pd} / \mathrm{Al}_{2} \mathrm{O}_{3}$ catalysts with organic thiol monolayers imparts significant selectivity improvements. Modification of $\mathrm{Pd} / \mathrm{Al}_{2} \mathrm{O}_{3}$ catalysts with 1-octadecanethiol enhanced the toluene selectivity from $35 \%$ to $82 \%$ under equivalent reaction conditions[37]. Use of a 1-adamantanethiol modifier improved the selectivity to a smaller extent, but also improved activity relative to the uncoated catalyst; this latter effect was attributed to the coating reducing accumulation of carbonaceous deposits during reaction.

Previous work for applications outside of catalysis has shown that it is often useful to employ mixed monolayers formed from two or more thiols. Surface properties such as wetting can be easily tuned between extreme values by altering the proportions of different thiolate modifiers[38, 39]. Mixed monolayers have also been used to improve the reactivity, stability and reversibility of Pd-based hydrogen sensors by modifying the nanoparticles with combinations of thiolates and amines[40]. To our knowledge, however, mixed monolayers have not been employed to tune catalyst performance. Use of mixed monolayers offers the potential for optimizing catalyst performance by achieving fine control over the surface environment. Perhaps more importantly, it also offers to opportunity to generate increased understanding both of monolayers organization and catalytic mechanism. For example, monolayers formed of two thiolates that substantially separate into islands on the surface would be expected to produce significantly different catalyst behavior compared to those that form well-mixed phases, as discussed below.

In this study, we report on the use of mixed monolayers of 1-octadecanethiol (C18) and 1-adamantanethiol (AT) as catalyst modifiers for benzyl alcohol HDO. The 
primary motivation for this study was to determine how mixing of two monolayers that resulted in much different catalyst performance (higher activity and moderate selectivity improvement for AT, much lower activity and high selectivity for C18) can be used to tune activity and selectivity. Of particular interest was assessing whether mixed monolayers could be used to create a unique active site environment, or alternatively whether mixing of monolayers largely resulted in the superposition of properties measured for C18- and AT-coated catalysts. 


\section{Experimental methods}

\subsection{Material and sample preparation}

Benzyl alcohol (99.8\%), 1-adamantanethiol (95\%), 1-octadecanethiol (98\%) and $5 \mathrm{wt} \% \mathrm{Pd} / \mathrm{Al}_{2} \mathrm{O}_{3}$ were acquired from Sigma-Aldrich. CO chemisorption on $\mathrm{Pd} / \mathrm{Al}_{2} \mathrm{O}_{3}$ was collected by Micromeritics ChemiSorb 2720 and the dispersion of $\mathrm{Pd} / \mathrm{Al}_{2} \mathrm{O}_{3}$ was $0.30 \pm 0.01$ at room temperature. 1-Octadecane- $\mathrm{d}_{37}$-thiol $(99 \%$ isotopic purity) and ultra-high-purity $\mathrm{CO}$ were respectively obtained from $\mathrm{C} / \mathrm{D} / \mathrm{N}$ isotopes and Specialty Gases of America. Ultra-high-purity $\mathrm{H}_{2}$ and $\mathrm{He}$ for the reactor system were obtained from Airgas.

Thiolate SAMs were deposited on $\mathrm{Pd} / \mathrm{Al}_{2} \mathrm{O}_{3}$ by immersing $150 \mathrm{mg} \mathrm{Pd} / \mathrm{Al}_{2} \mathrm{O}_{3}$ in 40 $\mathrm{mL}$ of a $5 \mathrm{mM}$ thiolate/ethanol solution for at least $12 \mathrm{~h}$. After removal from solution, the catalyst was rinsed in ethanol for $5 \mathrm{~h}$ and then the supernatant was decanted. The catalyst was dried in air at room temperature for $8 \mathrm{~h}$ before use. Mixed monolayers on $\mathrm{Pd} / \mathrm{Al}_{2} \mathrm{O}_{3}$ were prepared in the thiol solutions with the specified molar ratio of 1-adamantanethiol to 1-octadecanethiol, keeping the total thiol concentration at $5 \mathrm{mM}$. The ratio of sulfur to Pd (and thus the sulfur coverage) was measured using ICP-OES as described previously [36].

\subsection{Catalytic reaction}

The catalyst performance was evaluated in a packed bed continuous flow reactor after reaching steady state under atmospheric pressure at $433 \mathrm{~K}$. For comparison between different catalysts, the amount of catalyst was varied to achieve the same approximate conversion. The organic reactant was introduced by bubbling He through benzyl alcohol and mixing with $\mathrm{H}_{2}$ upstream of the reactor. Each reaction was run at least 300 min with $82 \mathrm{sccm}$ overall flow of $0.1 \mathrm{~mol} \%$ benzyl alcohol and $25 \mathrm{~mol} \% \mathrm{H}_{2}$. An Agilent Technologies 7890A gas chromatograph equipped with a flame ionization detector and a $30 \times 0.320 \mathrm{~mm}^{2}$ Agilent HP-5 capillary column was utilized to analyze feed and product samples. In this study, the activity of C18-coated catalysts was monitored over a period of 6 hours, and no change in performance was observed over this time following establishment of steady state. Previous studies have also indicated 
that the performance of thiol-modified catalyst did not significantly change over many hours of time on-stream during hydrogenation reactions, despite the fact that some changes in the monolayer organization occurred after exposure to reaction conditions $[29,31]$.

Apparent activation energies were measured under $0.1 \mathrm{~mol} \%$ benzyl alcohol and $25 \mathrm{~mol} \% \mathrm{H}_{2}$ with overall $82 \mathrm{sccm}$ flow rate and a reactor temperature from 413 to 443 K. For reaction order studies in benzyl alcohol, the results were collected under 25 mol\% $\mathrm{H}_{2}$ and overall $82 \mathrm{sccm}$ flow rate at $433 \mathrm{~K}$ reactor temperature with benzyl alcohol from $0.05 \%$ to $0.3 \mathrm{~mol} \%$.

\subsection{FT-IR analysis}

Fourier transform infrared analysis was performed with 100 scans at $4 \mathrm{~cm}^{-1}$ resolution using a Thermal Scientific Nicolet 6700 FT-IR and a Harrick reaction chamber. For measuring the vibrational spectrum of adsorbed $\mathrm{CO}$ with diffuse reflectance infrared fourier transform spectrum (DRIFTS) experiments, samples were placed in a closed and airtight chamber that was evacuated to 100 mtorr for $1 \mathrm{~h}$. Subsequently, CO was introduced into the cell and the measurement was taken after 2 min equilibration time. To provide an internal standard, 5\% (w/w) of 1,3,5-trimethoxybenzene was mixed with thiol-coated $\mathrm{Pd} / \mathrm{Al}_{2} \mathrm{O}_{3}$. For probe molecule adsorption DRIFTS experiments, the results were collected in the reaction chamber at $323 \mathrm{~K}$ during dosing $60 \mathrm{sccm}$ Ar flow of $0.1 \mathrm{~mol} \%$ chemical and $25 \mathrm{~mol} \% \mathrm{H}_{2}$. 


\section{Results/discussion}

\subsection{Thiolate monolayer composition studies}

We prepared thiolate-coated $\mathrm{Pd} / \mathrm{Al}_{2} \mathrm{O}_{3}$ catalysts using thiol solutions containing variable mole fractions of $\mathrm{C} 18$ and AT. Because the monolayer composition was not expected to match the solution composition-for example, C18 can pack more tightly on the surface, favoring its surface enrichment-we used three different techniques to estimate how monolayer composition was influenced by solution concentration.

The $\mathrm{CH}, \mathrm{CH}_{2}$ and $\mathrm{CH}_{3}$ stretching frequencies of thiol alkyl tails are in the region between 2800 to $3000 \mathrm{~cm}^{-1}$ in DRIFTS. Figure 1 shows the DRIFT spectra for this region for different thiolate compositions. For both pure and mixed monolayers, the $\mathrm{CH}_{2}$ symmetric stretch was observed around $2852 \mathrm{~cm}^{-1}$. The asymmetric stretching peak was found to be dependent on the relative concentrations of C18 and AT, gradually shifting from $2918 \mathrm{~cm}^{-1}$ (for the pure AT monolayer) to $2924 \mathrm{~cm}^{-1}$ (for the pure C18 monolayer). Additionally, because AT monolayers have no $\mathrm{CH}_{3}$ stretching mode while C18 monolayers exhibit an intense peak, the area under the asymmetric $\mathrm{CH}_{3}$ stretching peak at $2954 \mathrm{~cm}^{-1}$ can be used to directly determine the $\mathrm{C} 18$ fraction on $\operatorname{Pd}[41]$. The integrated $\mathrm{CH}_{3}$ asymmetric peak intensities from this analysis are shown in Table $\mathrm{S} 1$.

Because the overlap of the $\mathrm{CH}_{3}$ asymmetric stretching peak with other peaks may cause inaccuracy, fractional $\mathrm{C} 18$ coverage was also estimated by forming mixed monolayers from AT and perdeuterated C18 (D18) [42]. The advantage of this approach is that it separates DRIFTS peaks attributable to each component (since the C-D stretching modes from D18 are located in the $2000-2300 \mathrm{~cm}^{-1}$ region), allowing relative coverage to be estimated from a ratio of peak areas in each spectrum[43]. As shown in Figure 2(b), the intensity of carbon-deuterium stretching mode increased with D18 concentration in solution as expected. As shown in Figure 2(a), in the C-H stretching region of D18-coated catalyst, two stretching peaks at 2891 and $2883 \mathrm{~cm}^{-1}$ associated with CHD methylene groups[44], suggested some hydrogen isotopic impurities in the perdeuterated thiols. However, because there was no C-D stretching contribution from AT monolayers on the surface, the overall area of C-D stretching was used to estimate the C18 fraction on the surface. In Figure 2(b), the two peaks at 2089 
and $2195 \mathrm{~cm}^{-1}$ are assigned to symmetric and asymmetric $\mathrm{CD}_{2}$ stretching.

It should be noted that use of either FTIR to determine surface composition can be affected by changes in the orientation of adsorbed thiols as a function of coverage. Therefore, a final method for estimating fractional coverage employed elemental analysis rather than infrared spectroscopy. It is known that a bulky structure in AT molecules leads to formation of sparser monolayers and lower thiol coverage than $\mathrm{C} 18$ monolayers[45, 46]. Therefore, by assuming the thiol coverage on $\mathrm{Pd}$ is directly related to sulfur composition, the proportion of sulfur to palladium from ICP was employed to evaluate $\mathrm{C} 18$ fractional coverage.

$$
{ }_{\text {total }}=y_{A T}{ }_{A T}+y_{C 18} \quad C 18
$$

where $\theta_{\text {total }}$ is the overall proportion of sulfur to surface palladium for the mixed monolayers system, and $\theta_{\mathrm{AT}}$ and $\theta_{\mathrm{C} 18}$ are the ratio of sulfur to palladium for pure AT and C18 monolayers, respectively. The parameters $\mathrm{y}_{\mathrm{AT}}$ and $\mathrm{y}_{\mathrm{C} 18}$ are the AT and C18 mole fraction in the monolayers on the surface, where $\mathrm{y}_{\mathrm{AT}}+\mathrm{y}_{\mathrm{C} 18}=1$. In Table S2, the ICP results show that the sulfur content increased with $\mathrm{C} 18$ concentration and reached a maximum for pure $\mathrm{C} 18$ monolayers on $\mathrm{Pd}$, where the saturation coverage of the pure C18 monolayer was normalized to the theoretical C18 coverage on $\operatorname{Pd}(111)$ of 0.33 monolayers[47]. Through equation (1), the C18 fraction for each sample can be calculated and is shown in Figure 3.

Figure 3 shows a summary of the $\mathrm{C} 18$ mole fraction on the surface as a function of C18 mole fraction in solution $\left(\mathrm{x}_{\mathrm{C} 18}\right.$, defined such that $\left.\mathrm{x}_{\mathrm{C} 18}+\mathrm{x}_{\mathrm{AT}}=1\right)$ as evaluated by these different methods. All methods show qualitative agreement, and indicate the enrichment of $\mathrm{C} 18$ at the surface relative to the solution. Also shown in Figure 3 is a simple Langmuir adsorption isotherm model that was fit to the data. Model details are shown in the Supporting Information. As a crude approximation, this model assumes that each AT adsorbate occupies twice the surface area of a C18 adsorbate. The apparent deviations from the model trend are likely due to factors such as dispersion interactions between adsorbates and the inhomogeneity of surface sites on the supported Pd nanoparticles. 


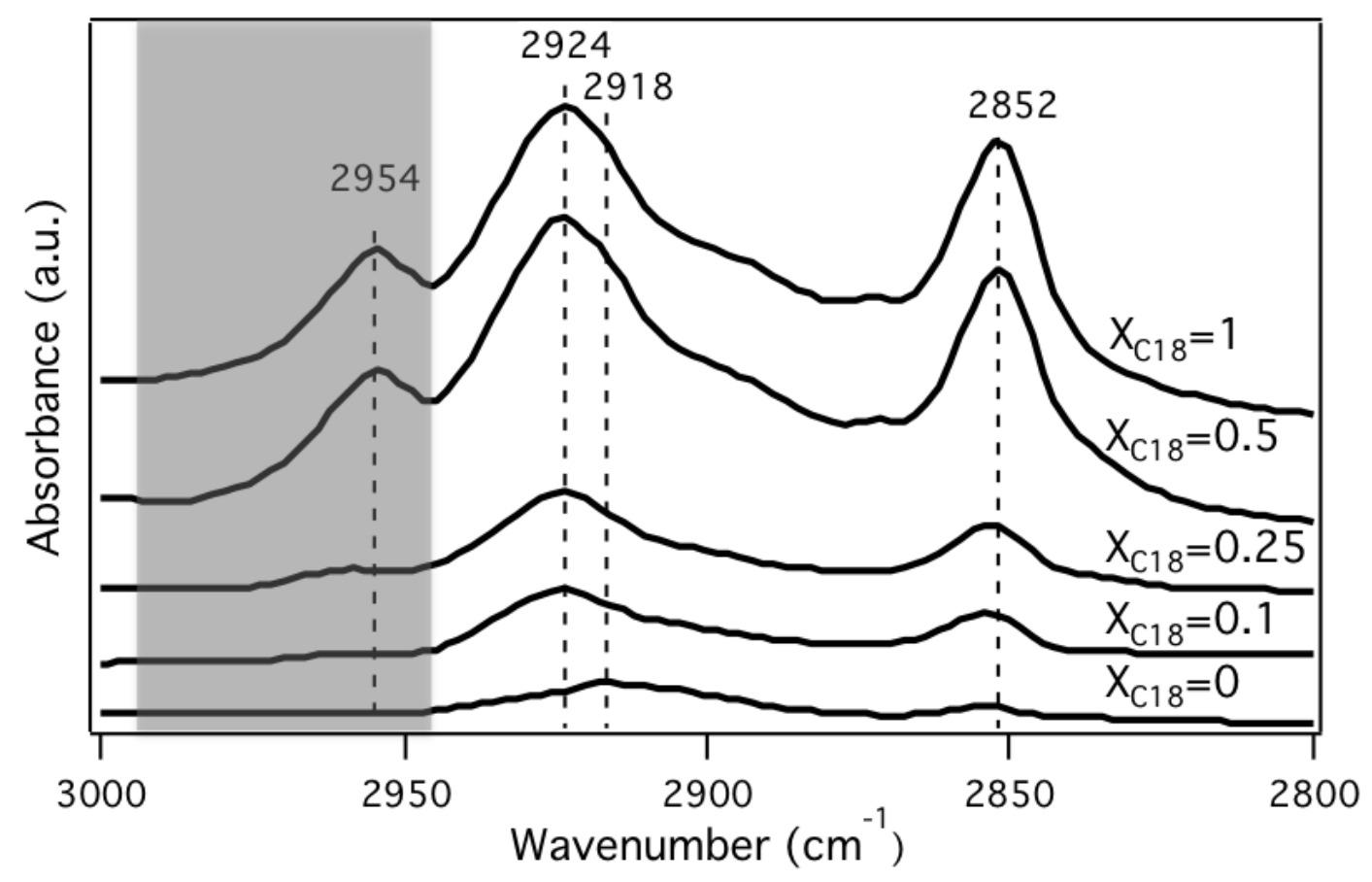

Figure 1: Representative DRIFTS of AT and C18 co-deposition on $\mathrm{Pd} / \mathrm{Al}_{2} \mathrm{O}_{3}$ at different solution composition. The peak at $2954 \mathrm{~cm}^{-1}$, highlighted in gray, is the $\mathrm{CH}_{3}$ asymmetric stretching mode for $\mathrm{C} 18$ fraction calculation.
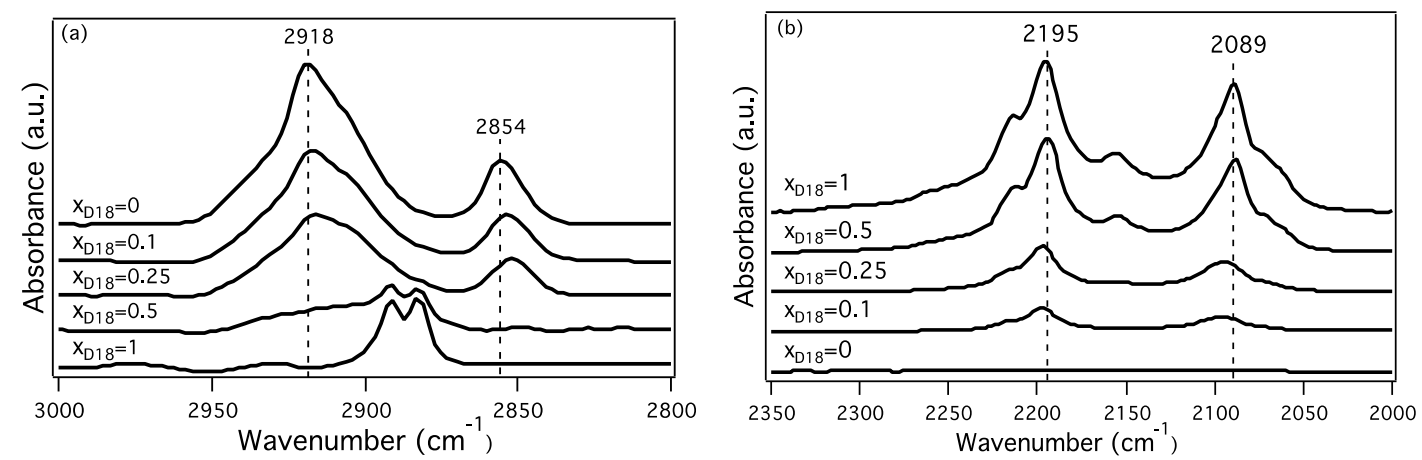

Figure 2: Representative DRIFTS of AT and perdeuterated C18 (D18) co-deposition on $\mathrm{Pd} / \mathrm{Al}_{2} \mathrm{O}_{3}$ at different solution composition (a) C-H stretching mode region (b) C-D stretching mode region 


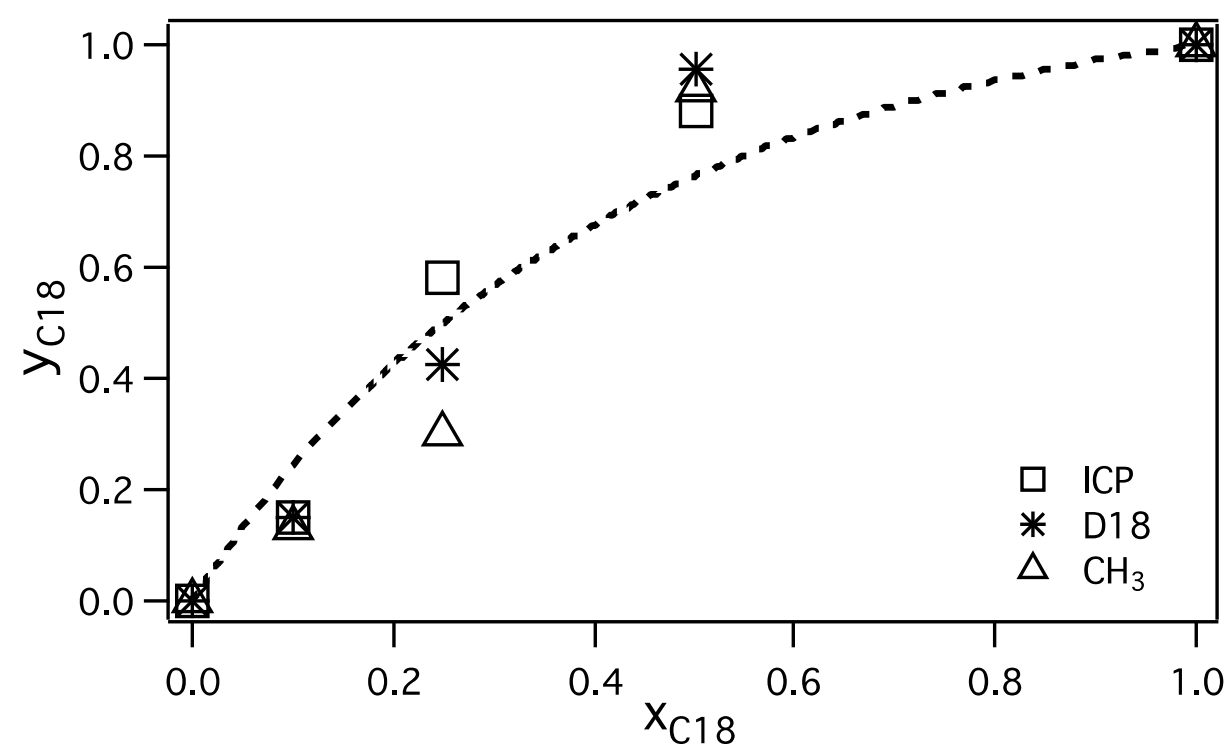

Figure 3. $\mathrm{C} 18$ mole fraction on $\mathrm{Pd} / \mathrm{Al}_{2} \mathrm{O}_{3}\left(\mathrm{y}_{\mathrm{C} 18}\right)$ estimated by post-reaction ICP results (ICP), the area of deuterated $\mathrm{C} 18$ stretching (D18) and $\mathrm{CH}_{3}$ stretching $\left(\mathrm{CH}_{3}\right)$ as a function of $\mathrm{C} 18$ mole fraction in ethanol $\left(\mathrm{x}_{\mathrm{C} 18}\right)$. The dashed line is a best-fit Langmuir isotherm model assuming one AT molecule occupies two sites (see Supporting Information).

\subsection{Catalytic performance studies}

The uncoated and coated catalysts were evaluated for their performance in the hydrogenation of benzyl alcohol. Figure 4 shows catalyst performance as a function of deposition mole fraction $\left(\mathrm{x}_{\mathrm{C} 18}\right)$ collected at a reaction temperature of $433 \mathrm{~K}$ and 0.1 mol\% benzyl alcohol. On uncoated Pd catalysts, the dominant product from benzyl alcohol was benzene and the selectivity to toluene was less than $22 \%$. As observed previously under somewhat different reaction conditions, deposition of AT monolayers improved the toluene selectivity significantly, and also resulted in higher reaction rate than the uncoated catalyst[37]. The improved activity has been attributed to weaker interactions of the phenyl ring of benzyl alcohol with the surface and reduced coke formation from benzene decomposition on $\mathrm{Pd}$ surface[30]. For pure C18-coated $\mathrm{Pd} / \mathrm{Al}_{2} \mathrm{O}_{3}$, toluene selectivity was improved to $85 \%$ and barely a trace of benzene was observed, but there was a large decrease in reaction rate. Some benzaldehyde was also formed; this was expected, as alcohol isomerization has previously been observed on 
thiolate-coated metals[34]. The catalyst performance was similar to that measured previously ( $83 \%$ selectivity to toluene) at approximately $40 \%$ conversion[37]. Moreover, because production of benzaldehyde is reversible whereas toluene formation is essentially irreversible under the reaction conditions, HDO selectivity actually improved with conversion. As shown in Figure 5, at near full (>95\%) conversion, toluene selectivity over the C18-coated catalyst reached 98\%. In contrast, toluene selectivity on the uncoated catalyst was $<30 \%$ near full conversion. The same trend was also observed using benzaldehyde as the reactant for HDO; in this case, the selectivity to toluene was also increased from $23 \%$ to $87 \%$ near full conversion after $\mathrm{C} 18$ modification (Figure S1).

For mixed monolayers-coated catalysts (Figure 4), increased C18 fraction resulted in a continuous increase in toluene selectivity. However, even a relatively small mole fraction of $\mathrm{C} 18$ in the deposition solution $\left(\mathrm{x}_{\mathrm{C} 18}=0.1\right)$ resulted in a major decrease in the reaction rate. As shown in Figure 3, the surface mole fraction of $\mathrm{C} 18\left(\mathrm{yC}_{18}\right)$ for such a mixture was determined to be around $15 \%$ at these conditions. The high sensitivity of activity to $\mathrm{C} 18$ mole fraction suggests that C18 and AT adsorbates did not strongly segregate to form islands on the catalyst surface; if a simple segregation model were adequate, the rate would only be expected to go down by $\sim 15 \%$ on this AT-rich surface. Therefore, these results show that mixing of C18 and AT monolayers does not result in a simple superposition of the performance of separately coated C18 and AT catalysts, but that the mixed monolayers actually exhibit distinct properties. It is not clear from these data, however, if the main factor resulting in decreased rate is a random distribution of $\mathrm{C} 18$ within the AT overlayer, or whether $\mathrm{C} 18$ may have filled defects that are responsible for a large proportion of the reactivity on AT-coated catalysts. We discuss this point in some detail below.

The fact that activity appeared to be more sensitive to C18 mole fraction, whereas selectivity was a more smoothly varying function of C18 mole fraction, is attributed to the fact that crowding by thiolates affected multiple reaction steps on the surface, but in different ways[10, 37]. That is, moderate crowding with AT is hypothesized to be sufficient to significantly weaken phenyl-surface interactions and prevent poisoning, 
while further crowding more strongly affects the availability of active sites for the HDO reaction.

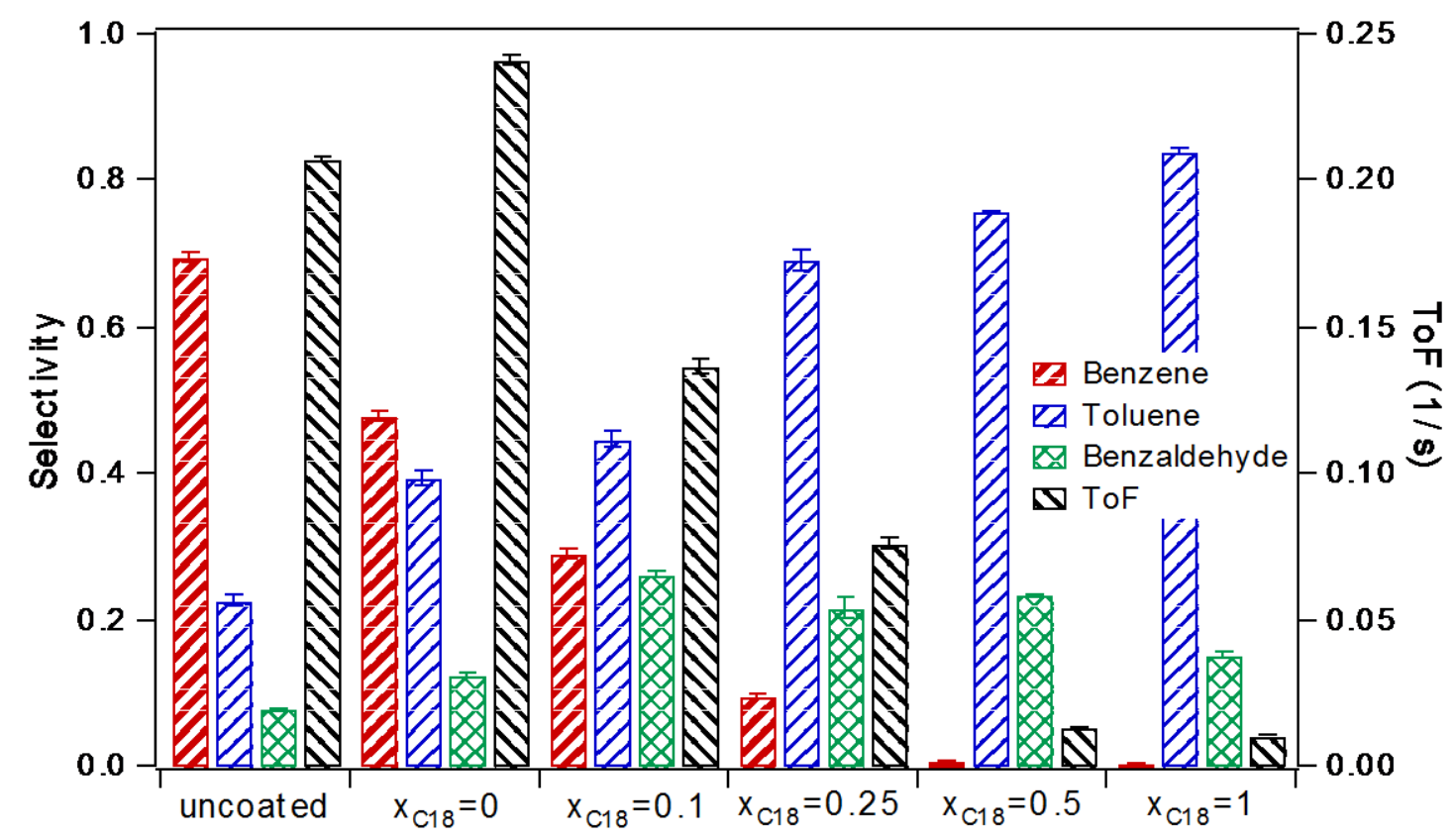

Figure 4: Benzyl alcohol selectivity and turnover frequency for uncoated, AT, mixed-monolayers and $\mathrm{C} 18$-coated $\mathrm{Pd} / \mathrm{Al}_{2} \mathrm{O}_{3}$ at $433 \mathrm{~K}$. The conversion was $48 \pm 3 \%$ in all cases.
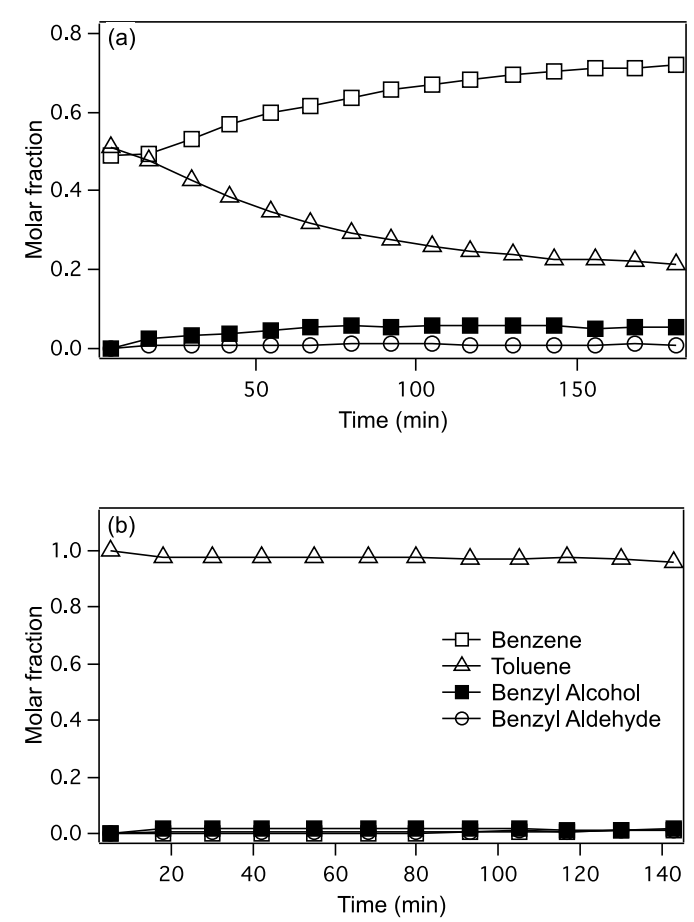
Figure 5: Evolution of the products and the remaining reactant during benzyl alcohol reactions over (a) 5.0mg uncoated $\mathrm{Pd} / \mathrm{Al}_{2} \mathrm{O}_{3}$ (b) $80.0 \mathrm{mg}$ C18-coated in the continuous reactor at $433 \mathrm{~K}$ with over $95 \%$ conversion.

\subsection{Site characterization}

\subsubsection{CO adsorption}

We used DRIFT spectra of adsorbed CO to measure the distribution of active sites on the catalysts. The adsorption of $\mathrm{CO}$ on various facets and sites is characterized by different stretching frequencies in the infrared spectrum, which makes $\mathrm{CO}$ a useful probe molecule[48-50]. DRIFTS results with different CO pressures for all Pd samples before and after reaction are shown in Figures S2 and S3. Because the post-reaction samples are thought to provide a better description of the site distribution under reaction conditions, here we focus on analysis of those samples. Figure 6 shows the DRIFTS results after saturation exposures of CO measured on catalysts that had been exposed to reaction conditions for $5 \mathrm{~h}$. Peaks at lower frequency $\left(<2000 \mathrm{~cm}^{-1}\right)$ are attributed to bridging CO on terraces and edges $\left(\sim 1950 \mathrm{~cm}^{-1}\right)$, and three-fold on (111) planes $\left(\sim 1840 \mathrm{~cm}^{-1}\right)[30]$. The peaks at higher frequency are attributed to linear $\mathrm{CO}$ on edges $\left(\sim 2040 \mathrm{~cm}^{-1}\right)$, corners and (111) planes $\left(\sim 2090 \mathrm{~cm}^{-1}\right)[51,52]$. As reported previously for catalysts exposed to similar furfural hydrogenation conditions, linear CO was found to account for a much higher fraction of the available sites on the C18-coated catalyst than on the uncoated catalyst[32]. As shown in Figure 6, the ratio of the high-frequency to low-frequency peak intensity increased as the fraction of $\mathrm{C} 18$ within the mixed monolayers increased. This result is more clearly represented in Figure 6(b), where the ratio of peak areas is reported for each catalyst as a function of $\mathrm{CO}$ pressure. At all CO pressures, the ratio was observed to increase as the AT fraction decreased.

While most of these trends were also observed on freshly prepared catalysts not exposed to reaction conditions, there are some interesting differences. Figure S4 shows the DRIFTS results obtained at saturating CO pressures on the freshly coated catalysts. The intensity of the CO stretching peaks was very low for C18-rich catalysts; the higher intensity measured after exposure to reaction conditions suggests that during 
reaction additional sites become open for reaction. The reorganization of thiolates on supported metal catalysts with hydrogen exposure following SAM deposition has previously been reported to produce more available sites for $\mathrm{CO}$ adsorption[53]. Furthermore, exposure to reaction conditions also apparently caused a change in the distribution of available sites for the uncoated catalysts. For uncoated catalysts, the linear CO peak position was observed at lower frequency $\left(2063 \mathrm{~cm}^{-1}\right)$ after reaction. This downward shift is attributed to a larger fraction of linear CO being bound to step and edge sites due to the hypothesized presence of carbonaceous deposits on the catalyst terraces and less linear $\mathrm{CO}$ adsorption on terrace after exposure to reaction conditions. The DRIFTS C-H stretching region of catalysts before and after reaction in Figure S5 is consistent with our hypothesis. The appearance of two broad $\mathrm{C}-\mathrm{H}$-stretching peaks after $5 \mathrm{~h}$ reaction and 30 min purging with the flow of $\mathrm{Ar}$ and $\mathrm{H}_{2}$, indicated that a surface carbonaceous layer was left on the unmodified surface. Some extent of hydrocarbon deposition on AT-coated catalysts was also observed, suggesting that the less dense AT layer does not fully prevent reactant decomposition to produce a carbonaceous layer. On the other hand, for the C18-coated catalyst it appears that any contribution from additional carbonaceous deposits was small, consistent with a strong decrease in formation of deposits on the densely coated layer. After reaction, the C-H stretching intensity of AT and C18 monolayers was attenuated, likely due to partial desorption of physisorbed thiols and decomposition of some alkyl tails in the monolayers[32]. Additionally, the asymmetric $\mathrm{CH}_{2}$ stretching peak shifted from 2924 $\mathrm{cm}^{-1}$ to $2920 \mathrm{~cm}^{-1}$, indicating that the $\mathrm{C} 18$ conformational order was increased due to SAM reorganization in the $\mathrm{H}_{2}$ environment [53]. 

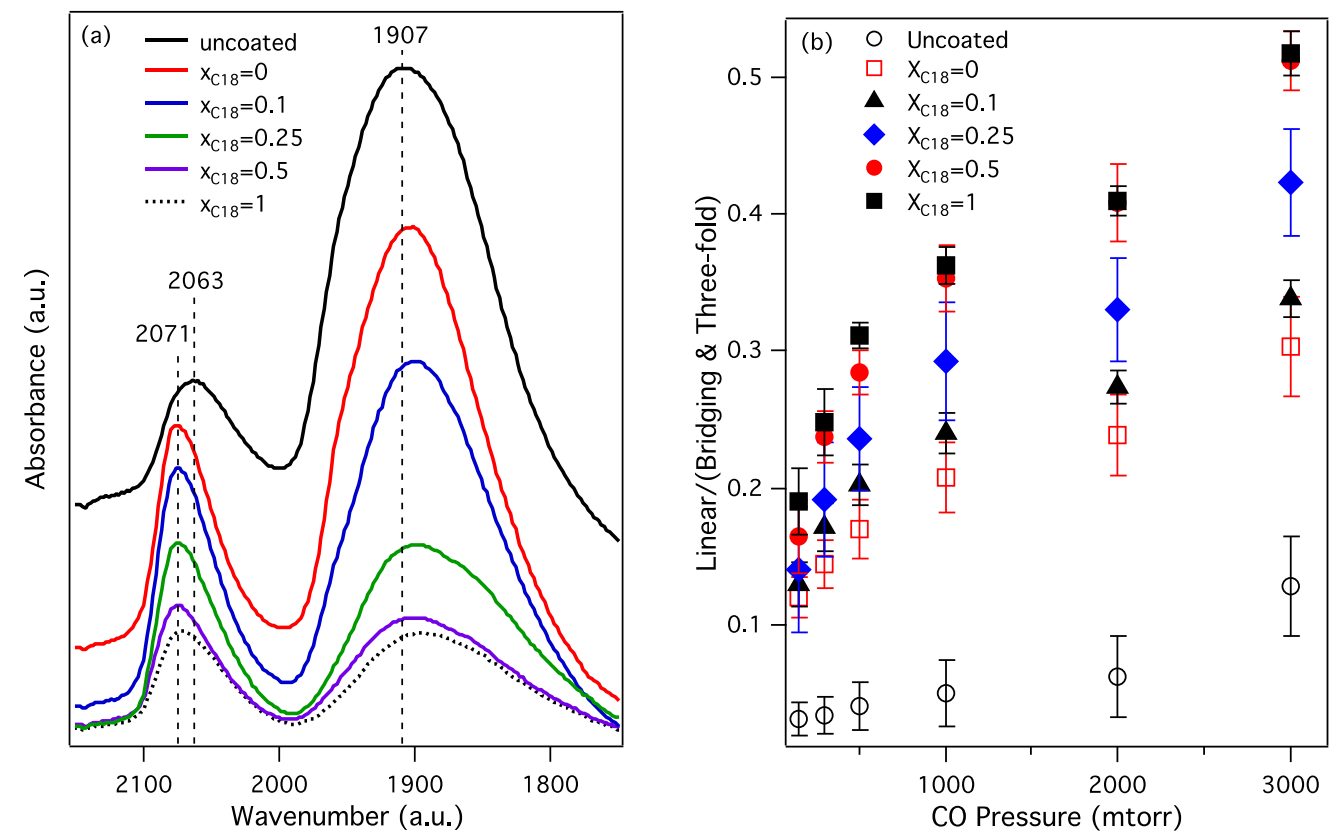

Figure 6: DRIFTS for uncoated and thiol-coated $\mathrm{Pd} / \mathrm{Al}_{2} \mathrm{O}_{3}$ after $5 \mathrm{~h}$ reaction. (a) $\mathrm{CO}$ stretching region for uncoated, AT, mixed thiol and $\mathrm{C} 18$-coated $\mathrm{Pd} / \mathrm{Al}_{2} \mathrm{O}_{3}$ under 3000 mtorr CO pressure.(b) The area ratio of linear to bridging and three-fold adsorptions functions as $\mathrm{CO}$ pressure in mtorr.

\subsubsection{Benzyl alcohol adsorption}

To confirm that benzyl alcohol DC to benzene predominantly occurred on Pd terrace sites, in situ DRIFT spectra were collected during dosing of benzyl alcohol on uncoated, AT, mixed thiol and $\mathrm{C} 18$-coated $\mathrm{Pd} / \mathrm{Al}_{2} \mathrm{O}_{3}$ catalysts. As shown in Figure 7, following benzyl alcohol exposure on uncoated $\mathrm{Pd}$, an intense $\mathrm{CO}$ peak was observed at $1880 \mathrm{~cm}^{-1}$. Interestingly, negligible amounts of $\mathrm{CO}$ were detected on linear sites (at higher frequency). Because $\mathrm{CO}$ is the side product from the decarbonylation of benzyl alcohol, preferential population of the $1880 \mathrm{~cm}^{-1}$ peak indicates that decarbonylation likely occurs on specific types of surface sites, particularly on particle terraces. On the AT-modified catalyst, the decreased peak frequency is attributed to a reduced extent of $\mathrm{CO}$ dipole coupling from lower $\mathrm{CO}$ coverage. When a mixed $\mathrm{C} 18$ monolayer was used, the resulting $\mathrm{CO}$ peak decreased dramatically in intensity and shifted from $1876 \mathrm{~cm}^{-1}$ to $1813 \mathrm{~cm}^{-1}$, presumably due to less terrace availability for bridging CO adsorption and the further reduced extent of dipole coupling interaction by higher thiol coverage. The 
CO peak was unobservable on C18-coated Pd surface, consistent with the hypothesis that dense monolayers blocked most of the contiguous sites on terraces for flat-lying benzyl alcohol and prevented DC to benzene and CO, promoting high selectivity[37]. Benzene and toluene were not observable in DRIFTS during benzyl alcohol exposure due to serious overlapping with other signals and weaker bonding strength with the catalyst, but the appearance of a shoulder around $1390 \mathrm{~cm}^{-1}$ indicates benzaldehyde was generated from benzyl alcohol for C18-coated catalyst[13].

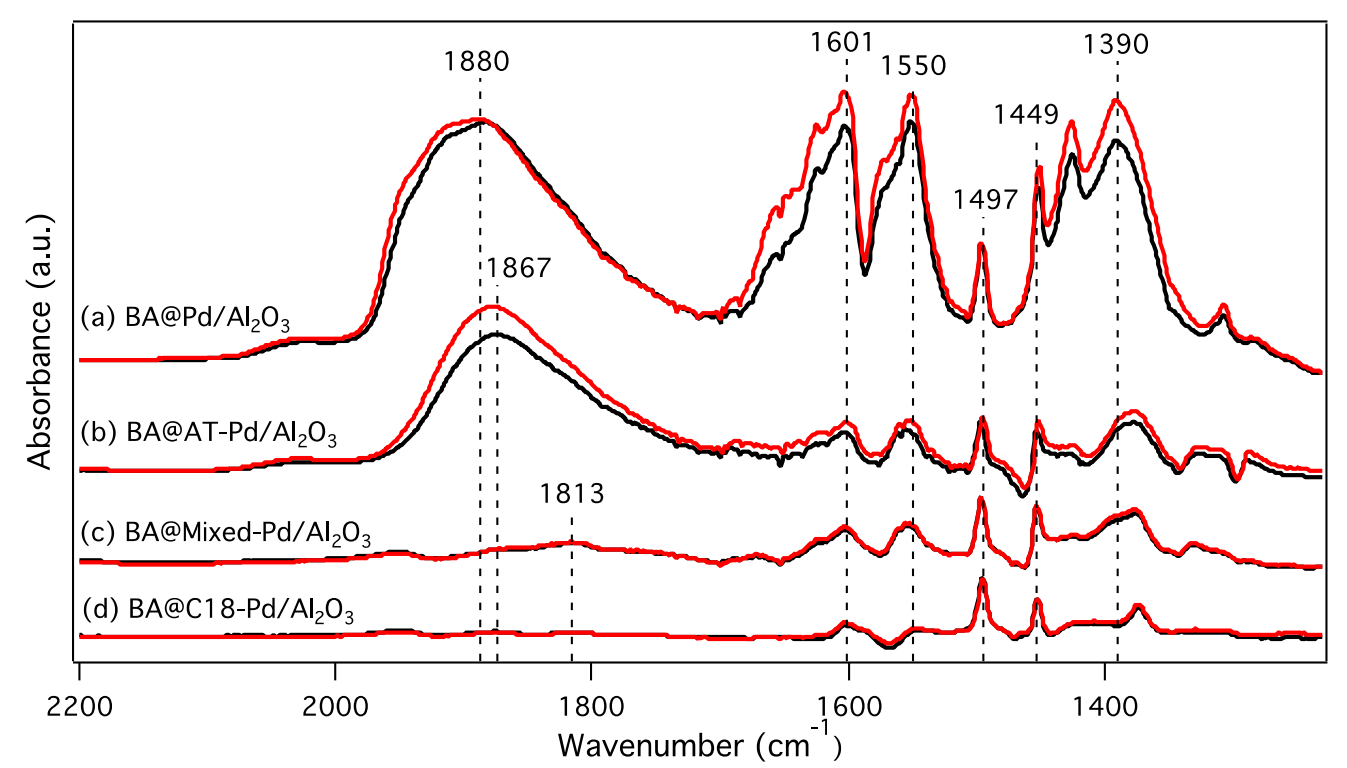

Figure 7: In situ DRIFTS of benzyl alcohol and $25 \% \mathrm{H}_{2}$ in $\mathrm{Ar}$ flow on $\mathrm{Pd} / \mathrm{Al}_{2} \mathrm{O}_{3}$ at 323 K. (a) benzyl alcohol on uncoated $\mathrm{Pd} / \mathrm{Al}_{2} \mathrm{O}_{3}$ (b) benzyl alcohol on AT-coated $\mathrm{Pd} / \mathrm{Al}_{2} \mathrm{O}_{3}$ (c) benzyl alcohol on mixed thiol-coated $\mathrm{Pd} / \mathrm{Al}_{2} \mathrm{O}_{3}\left(\mathrm{x}_{\mathrm{C} 18}=0.25\right)$ (d) benzyl alcohol on C18-coated $\mathrm{Pd} / \mathrm{Al}_{2} \mathrm{O}_{3}$. Bold black and red spectra represent the dosing experiment and purging with Ar for 1h, respectively.

\subsection{Kinetic studies}

Kinetic studies can provide useful information regarding reaction mechanisms on uncoated and thiolate-coated surfaces[32]; to understand how the coatings influenced rate parameters, we therefore measured changes in differential rates as a function of temperature and feed composition. The reaction rates for uncoated, AT and C18-coated catalyst were collected from 413 to $443 \mathrm{~K}$ to determine apparent activation energies. 
Arrhenius plots for this analysis are shown in Figure S6, and the results are summarized in Table 1. The very low yield of benzene on the C18-coated catalyst precluded measurement of an activation energy for DC on that surface. Apparent activation energies remained essentially the same between catalysts for the undesired benzene production pathway, suggesting that the decreased benzene yield on the AT-coated surface is attributed to a decrease in the density of active sites for that reaction rather than a change in barrier. The HDO apparent activation energy was measured to be approximately $108 \mathrm{~kJ} / \mathrm{mol}$ on the $\mathrm{C} 18$-coated catalyst. This is similar to the predicted value of $\sim 100 \mathrm{~kJ} / \mathrm{mol}$ measured on a crowded $\operatorname{Pd}(111)$ single crystal[10, 37], but may be slightly different due to the hypothetical role of step sites. In any case, the HDO activation energy on the C18-coated catalyst is in the range expected for rate-limiting $\mathrm{C}-\mathrm{O}$ dissociation. In contrast, the activation energy on the uncoated and AT-coated catalysts was measured to be quite low, far below that associated with the C-O dissociation barrier, indicating a complex mechanism. A low HDO activation energy was similarly measured for furfuryl alcohol on uncoated Pd catalysts[14]. While the origins of this low barrier are unclear, they are proposed to be related to activation of a process (such as benzyl alcohol decomposition to block active sites) that limits the increase in rate at high temperatures.

Table 1. Apparent Activation Energies for Benzyl Alcohol DC, HDO and DH, where the reported error bar is from the standard deviation of the slope of the linear regression analysis in the Arrhenius plot.

\begin{tabular}{c|c|c|c}
\hline \hline & DC E $_{\mathrm{a}}(\mathrm{KJ} / \mathrm{mol})$ & HDO E $_{\mathrm{a}}(\mathrm{KJ} / \mathrm{mol})$ & $\mathrm{DH} \mathrm{E}_{\mathrm{a}}(\mathrm{KJ} / \mathrm{mol})$ \\
\hline \hline Uncoated & $101 \pm 13$ & $5 \pm 4$ & $36 \pm 5$ \\
\hline $\mathrm{AT}$ & $107 \pm 10$ & $9 \pm 7$ & $44 \pm 5$ \\
\hline $\mathrm{C} 18$ & - & $108 \pm 5$ & $82 \pm 6$ \\
\hline \hline
\end{tabular}

Reaction orders in benzyl alcohol were also measured for the uncoated, AT and C18-coated catalysts were studies by varying benzyl alcohol feed concentration at $433 \mathrm{~K}$ and are summarized in Table S3, with kinetic plots shown in Figure S7. There was no obvious significant reaction order change between catalysts, although the reaction order for HDO was significantly higher for the C18-coated surface $(\sim 0.5)$ than for the AT-coated and uncoated catalysts $(\sim 0.2)$, suggesting a reduced extent of site blocking by the reactant. The overall trends in the reaction order and activation energy 
for the uncoated and C18-coated catalysts are similar to those observed previously for furfuryl alcohol, though the difference in HDO activation energies in the latter case were smaller in the latter study, while the differences in reaction order were greater[32].

\subsection{Discussion}

In this section, a mechanism is proposed for the catalyst performance improvement by thiol modification, and then the relationship between monolayer composition and catalyst performance, and possible explanations for observed trends is discussed. As shown in Scheme 1, previous studies have revealed that DC to benzene and HDO to toluene proceed through flat-lying and upright benzyl alcohol conformations on Pd(111), respectively[10]. On an AT-coated Pd surface, flat-lying benzyl alcohol hypothetically could still be formed because the bulky AT molecules formed sparse monolayers, but the repulsive interaction between monolayers and flat-lying conformation reduced the amount of flat-lying benzyl alcohol and improved the catalyst selectivity[31]. With higher C18 fractions in the monolayers, the increased thiol coverage hypothetically reduced amount of contiguous active sites on terrace and essentially eliminated the flat-lying conformation leading to DC. For pure C18 monolayers, stronger interactions between carbon chains causes C18 molecules preferentially form ordered and dense monolayers on Pd terraces, so edge sites and monolayers defects become the main active sites, which are only available for upright benzyl alcohol and HDO to toluene.

Scheme 1. Proposed benzyl alcohol reaction mechanism on $\operatorname{Pd}(111)$. Scheme adapted from reference 10 . 


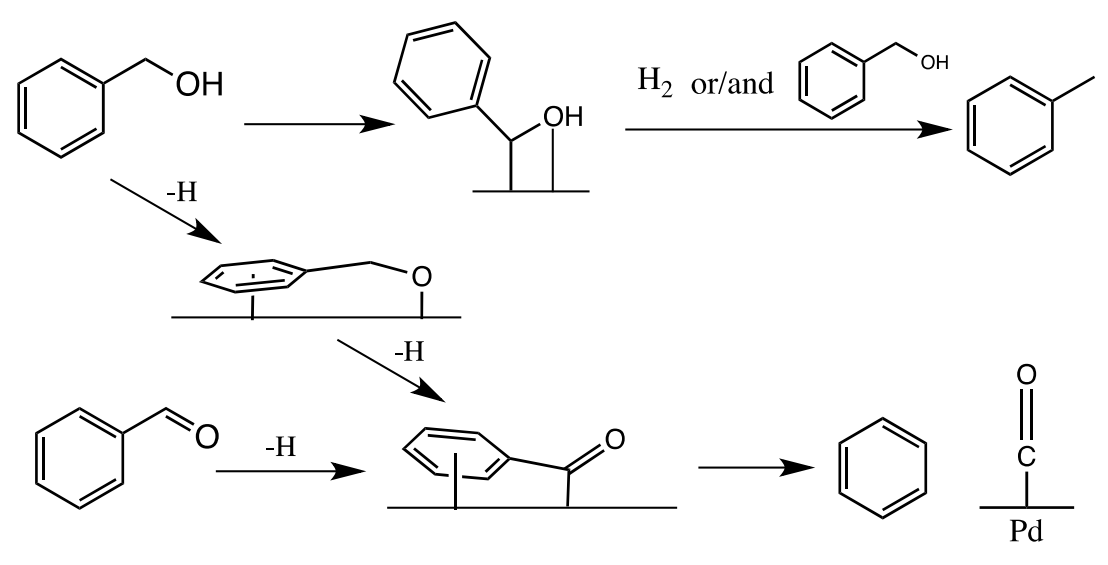

Several investigators have studied the structure of mixed monolayers on metal surfaces. At high ratios of AT to 1-dodecanethiol in co-adsorption on Au films, Dameron et al. found that 1-dodecanethiol was randomly distributed in the AT overlayer[45]. However, in sequential deposition of one alkanethiol followed by another, long chain thiol molecules have been found to displace shorter chains with the initial displacement occurring at defect sites such as grain boundaries, with further accumulation leading to segregation $[54,55]$. Similar phenomena were observed in the replacement of 1-adamantanethiol with 1-dodecanethiol[43, 45, 56, 57].

The structure of mixed monolayers is likely even more complex on the supported metal nanoparticles that are the substrate in this study. Surface crowding with thiolates clearly influences the site distribution on catalysts, as illustrated in Figure 6; as crowding is increased, the fraction of $\mathrm{CO}$ that bound to linear step and edge sites was found to increase. Our results are consistent with a picture where C18 incorporated into predominantly AT monolayers preferentially blocks sites on particle terraces, perhaps by occupying defects in the AT layers. Because C18 has a smaller "footprint" on the Pd surface, it is logical that it may be able to better "fit" in locations where a defect in the AT layer would exist. More effective crowding on terraces could explain the very large drop in rate with small amounts of $\mathrm{C} 18$ in the monolayer.

The increase in the ratio of edge to terrace sites closely mirrors the increased selectivity toward toluene. Figure 8 shows thiolate coverage trends in the relative rates of deoxygenation and decarbonylation, here plotted as the toluene rate divided by the sum of the toluene and benzene rates. On the same axis, the ratio of the area under 
the two major CO DRIFTS peaks is plotted, using a similar ratio of the linear CO area divided by the sum of the areas of the linear and multisite CO peaks, normalized so that the ratio has a maximum value of unity for the reported data. The correspondence in the selectivity trends with the relative abundance of different types of sites strongly suggests that the selectivity trends observed for mixed monolayers can largely be interpreted in terms of changes in the site distribution. That is, increased abundance of C18 has a much stronger poisoning effect on terrace sites than edge sites, leading to a continuous improvement in selectivity at the cost of activity. It is important to note that the relative fraction of linear $\mathrm{CO}$ versus $\mathrm{CO}$ bound in hollow and bridge sites provides an incomplete picture of structure sensitivity, and it would be preferable to relate rates to specific types of surface facets. Ongoing work in our laboratory is aimed at a more thorough assessment of the reactivity on different facets. The proposed reaction sites for benzyl alcohol on Pd surface are depicted in Scheme 2.

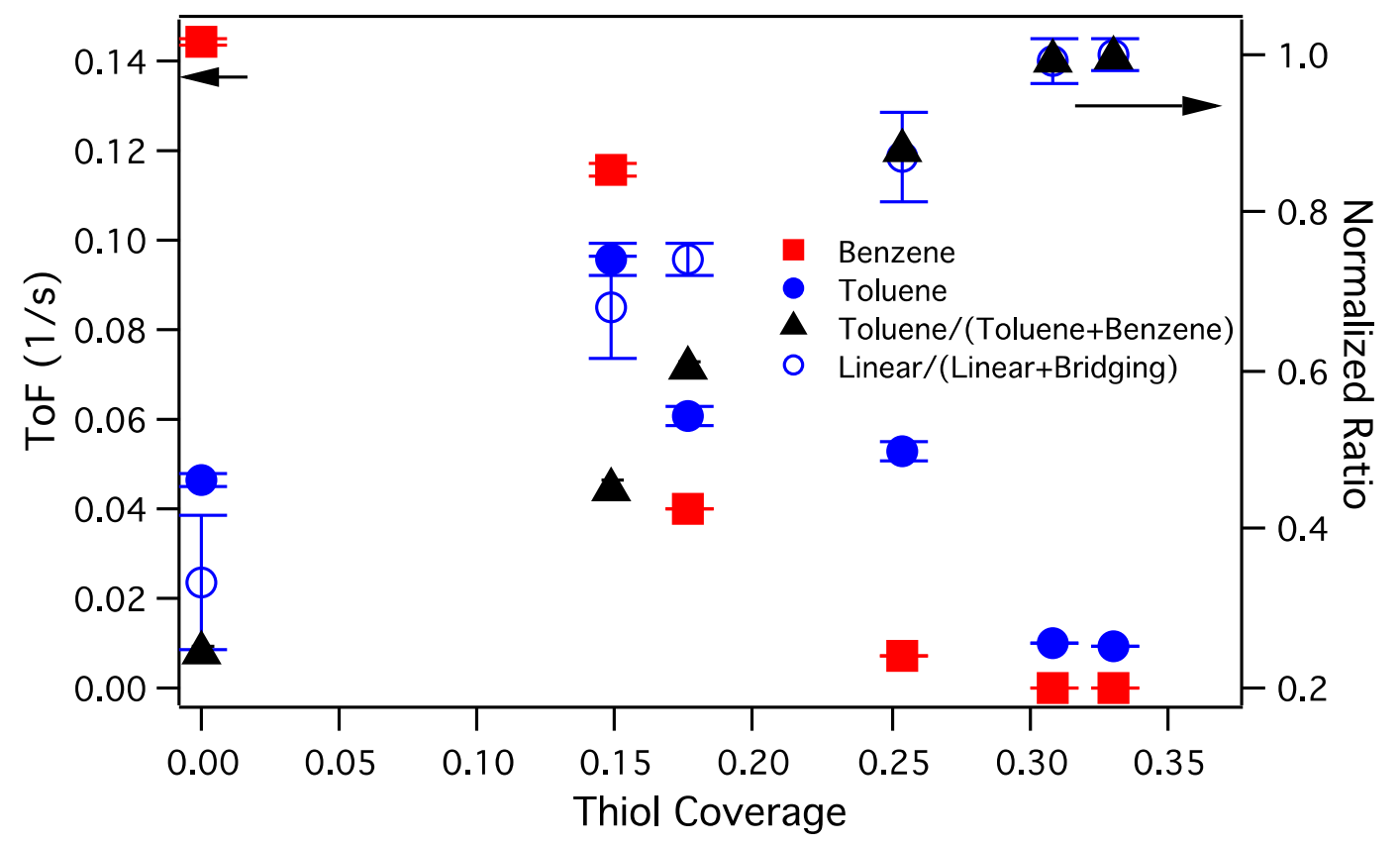

Figure 8: Product turnover frequency (solid squares and circles) and the ratios of those turnover frequencies (solid triangles) as a function of thiol coverage. Also shown is the post-reaction area ratio (open circles) of linear to bridging and three-fold adsorption as a function of thiol coverage estimated by ICP results from post-reaction samples.

Figure 8 also shows the rate of formation of specific products as a function of 
measured total thiol coverage, which was varied by controlling the relative amounts of AT and C18 during deposition. The rate of toluene formation was found to rise significantly after AT modification, and then drop with increasing total thiol coverage. As discussed already, the initial rise in rate with thiol coverage is attributed to the AT monolayer preventing accumulation of carbonaceous deposits that poison the reaction. In contrast, the DC rate to benzene dropped by approximately $20 \%$ after AT modification, but then a further $\sim 60 \%$ upon incorporation of a small amount of C18.

Scheme 2: Proposed reaction sites on uncoated Pd surface for benzyl alcohol. HDO to toluene was the prevailing reaction on edge sites while DC to benzene mainly occurs on Pd terrace sites.

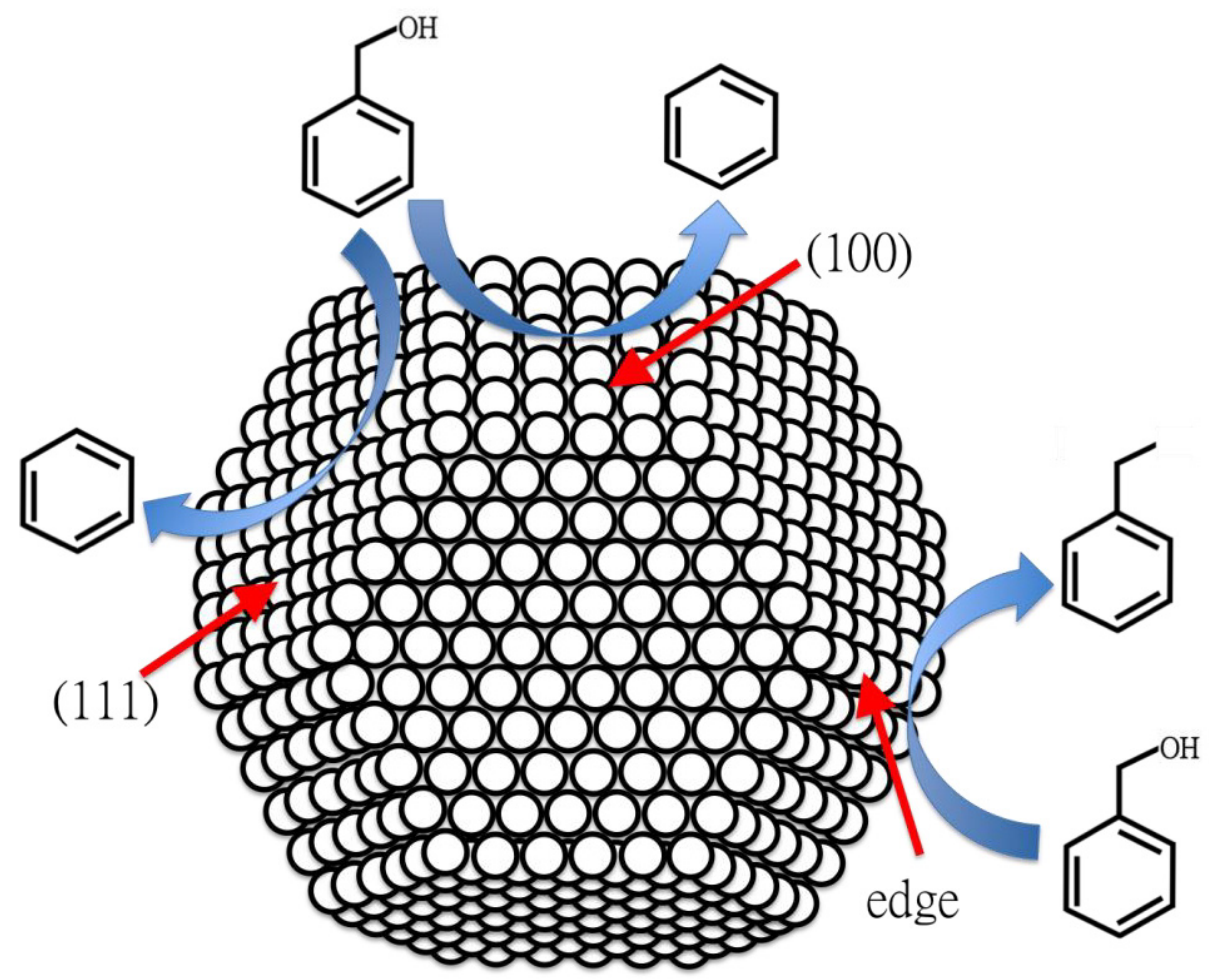

These results suggest that mixed monolayers can potentially be used to produce catalysts with useful performance by eliminating ensembles of surface sites in a different fashion than the independent mixture components. This can allow for tuning of catalyst performance; as shown in Figure 8 , by using an $\sim 40 \% \mathrm{C} 18$ mole fraction in an AT monolayer (total thiolate coverage of $\sim 0.26$ ), the HDO rate was decreased by less 
than a factor of 2 compared to pure AT, while the DC rate was cut by a factor of approximately 10. Moreover, for this mixed monolayer catalyst, the HDO rate was the same as that on the uncoated catalyst, but the selectivity for HDO over DC approached $90 \%$. That is, the use of mixed monolayers allowed the same production rate of toluene with a drastically decreased production of the undesired product benzene. 


\section{Conclusion:}

Mixed monolayers of AT and $\mathrm{C} 18$ were produced on $\mathrm{Pd} / \mathrm{Al}_{2} \mathrm{O}_{3}$ catalysts from deposition solutions of variable composition. Characterization with DRIFTS and ICP indicated that the surface was enriched in C18. After AT modification, both the selectivity to toluene and the activity were improved; these effects were attributed to weakened interactions of the phenyl ring of benzyl alcohol with the surface and to reduced formation of carbonaceous species on the surface, respectively. As the fractional C18 coverage was increased, the selectivity to toluene increased and the selectivity to benzene decreased at the cost of activity. DRIFTS studies showed that increased $\mathrm{C} 18$ fraction resulted in large reductions in the availability of terrace sites for DC to benzene by selective poisoning. A $60 \%$ drop in the DC rate from introduction of only $\sim 15 \% \mathrm{C} 18$ fraction in the mixed monolayers indicated that changes in catalyst performance could not be understood based on a simple superposition of the individual AT and C18 components, but rather that those components were mixed in a way that yielded distinct properties. This ability to control properties can be useful in catalyst design, or in understanding the mechanism for catalytic reactions. 


\section{AUTHOR INFORMATION}

\section{Corresponding Author}

*E-mail: Will.Medlin@colorado.edu

\section{ACKNOWLEDGMENT}

The authors acknowledge support from the National Science Foundation for funding this research through grant number CBET- 1160040. 


\section{References}

[1] M. Wellisch, G. Jungmeier, A. Karbowski, M.K. Patel, M. Rogulska, Biorefinery systems -potential contributors to sustainable innovation, Biofuels, Bioproducts and Biorefining, 4 (2010) 275-286.

[2] J.N. Chheda, G.W. Huber, J.A. Dumesic, Liquid-phase catalytic processing of biomass-derived oxygenated hydrocarbons to fuels and chemicals, Angewandte Chemie, 46 (2007) 7164-7183.

[3] J.W. Medlin, Understanding and Controlling Reactivity of Unsaturated Oxygenates and Polyols on Metal Catalysts, ACS Catalysis, 1 (2011) 1284-1297.

[4] G.W. Huber, J.N. Chheda, C.J. Barrett, J.A. Dumesic, Production of liquid alkanes by aqueous-phase processing of biomass-derived carbohydrates, Science, 308 (2005) 1446-1450.

[5] A. Enoki, G.P. Goldsby, M.H. Gold, belta-Ether Cleavage of the Lignin Model Compound 4-Ethoxy-3-methoxyphenylglycerol- -guaiacyl Ether and Derivatives by Phanerochaete chrysosporium, archives of microbiology, 129 (1981) 141-145. [6] M. TIEN, T.K. KIRK, Lignin-Degrading Enzyme from the Hymenomycete Phanerochaete chrysosporium Burds, Science, 221 (1983) 661-663.

[7] M. TIEN, T.K. KIRK, Lignin-degrading enzyme from Phanerochaete chrysosporium- Purification, characterization, and catalytic properties of a unique H202-requiring oxygenase, Proc. Natl. Acad. Sci. USA, 81 (1984) 2280-2284.

[8] G. Jiang, D.J. Nowakowski, A.V. Bridgwater, Effect of the Temperature on the Composition of Lignin Pyrolysis Products, Energy \& Fuels, 24 (2010) 4470-4475.

[9] D. Shi, J.M. Vohs, Lignin-derived oxygenate reforming on a bimetallic surface: The reaction of benzaldehyde on Zn/Pt(111), Surface Science, (2015).

[10] S.H. Pang, A.M. Román, J.W. Medlin, Adsorption Orientation-Induced Selectivity Control of Reactions of Benzyl Alcohol on Pd(111), The Journal of Physical Chemistry C, 116 (2012) 13654-13660.

[11] R.M. Williams, J.W. Medlin, Benzyl alcohol oxidation on pd(111): aromatic binding effects on alcohol reactivity, Langmuir : the ACS journal of surfaces and colloids, 30 (2014) 4642-4653.

[12] D. Ferri, C. Mondelli, F. Krumeich, A. Baiker, Discrimination of Active Palladium Sites in Catalytic Liquid-Phase Oxidation of Benzyl Alcohol, the journal of physical Chemistry B letters, 110 (2006) 22982-22986. 
[13] C. Keresszegi, D. Ferri, T. Mallat, A. Baiker, Unraveling the Surface Reactions during Liquid-Phase Oxidation of Benzyl Alcohol on Pd:Al203 an in Situ ATR-IR Study, The Journal of Physical Chemistry B, 109 (2005) 958-967.

[14] S.H. Pang, J.W. Medlin, Adsorption and Reaction of Furfural and Furfuryl Alcohol on Pd(111): Unique Reaction Pathways for Multifunctional Reagents, ACS Catalysis, 1 (2011) 1272-1283.

[15] M.A. Vannice, D. Poondi, The Effect of Metal-Support Interactions on the Hydrogenation of Benzaldehyde and Benzyl Alcohol, Journal of Catalysis, 169 (1997) 166-175.

[16] F. Pinna, F. Menegazzo, M. Signoretto, P. Canton, G. Fagherazzi, N. Pernicone, Consecutive hydrogenation of benzaldehyde over $\mathrm{Pd}$ catalysts Influence of supports and sulfur poisoning, Applied Catalysis A: General, 219 (2001) 195-200. [17] X. Wang, G. Wu, N. Guan, L. Li, Supported Pd catalysts for solvent-free benzyl alcohol selective oxidation: Effects of calcination pretreatments and reconstruction of Pd sites, Applied Catalysis B: Environmental, 115-116 (2012) 7-15.

[18] L.F. Liotta, A.M. Venezia, G. Deganello, A. Longo, A. Martorana, Z. Schay, L. Guczi, Liquid phase selective oxidation of benzyl alcohol over Pd-Ag catalysts supported on pumice, Catalysis Today, 66 (2001) 271-276.

[19] Y. Chen, H. Lim, Q. Tang, Y. Gao, T. Sun, Q. Yan, Y. Yang, Solvent-free aerobic oxidation of benzyl alcohol over $\mathrm{Pd}$ monometallic and $\mathrm{Au}-\mathrm{Pd}$ bimetallic catalysts supported on SBA-16 mesoporous molecular sieves, Applied Catalysis A: General, 380 (2010) 55-65.

[20] C. Della Pina, E. Falletta, M. Rossi, Highly selective oxidation of benzyl alcohol to benzaldehyde catalyzed by bimetallic gold-copper catalyst, Journal of Catalysis, 260 (2008) 384-386.

[21] S. Marx, A. Baiker, Beneficial Interaction of Gold and Palladium in Bimetallic Catalysts for the Selective Oxidation of Benzyl Alcohol, Journal of The American Chemical Society, 113 (2009) 6191-6201.

[22] X. Yang, C. Huang, Z. Fu, H. Song, S. Liao, Y. Su, L. Du, X. Li, An effective Pd-promoted gold catalyst supported on mesoporous silica particles for the oxidation of benzyl alcohol, Applied Catalysis B: Environmental, 140-141 (2013) 419-425.

[23] N. Dimitratos, J.A. Lopez-Sanchez, D. Morgan, A.F. Carley, R. Tiruvalam, C.J. Kiely, D. Bethell, G.J. Hutchings, Solvent-free oxidation of benzyl alcohol using 
Au-Pd catalysts prepared by sol immobilisation, Physical chemistry chemical physics : PCCP, 11 (2009) 5142-5153.

[24] D.I. Enache, D. Barker, J.K. Edwards, S.H. Taylor, D.W. Knight, A.F. Carley, G.J. Hutchings, Solvent-free oxidation of benzyl alcohol using titania-supported gold-palladium catalysts: Effect of $\mathrm{Au}-\mathrm{Pd}$ ratio on catalytic performance, Catalysis Today, 122 (2007) 407-411.

[25] P. Miedziak, M. Sankar, N. Dimitratos, J.A. Lopez-Sanchez, A.F. Carley, D.W. Knight, S.H. Taylor, C.J. Kiely, G.J. Hutchings, Oxidation of benzyl alcohol using supported gold-palladium nanoparticles, Catalysis Today, 164 (2011) 315-319.

[26] C.Y. Ma, B.J. Dou, J.J. Li, J. Cheng, Q. Hu, Z.P. Hao, S.Z. Qiao, Catalytic oxidation of benzyl alcohol on $\mathrm{Au}$ or $\mathrm{Au}-\mathrm{Pd}$ nanoparticles confined in mesoporous silica, Applied Catalysis B: Environmental, 92 (2009) 202-208.

[27] T. Chen, F. Zhang, Y. Zhu, Pd Nanoparticles on Layered Double Hydroxide as Efficient Catalysts for Solvent-Free Oxidation of Benzyl Alcohol Using Molecular Oxygen: Effect of Support Basic Properties, Catalysis Letters, 143 (2012) 206-218.

[28] M. Sankar, E. Nowicka, R. Tiruvalam, Q. He, S.H. Taylor, C.J. Kiely, D. Bethell, D.W. Knight, G.J. Hutchings, Controlling the duality of the mechanism in liquid-phase oxidation of benzyl alcohol catalysed by supported $\mathrm{Au}-\mathrm{Pd}$ nanoparticles, Chemistry, 17 (2011) 6524-6532.

[29] S.T. Marshall, M. O’Brien, B. Oetter, A. Corpuz, R.M. Richards, D.K. Schwartz, J.W. Medlin, Controlled selectivity for palladium catalysts using self-assembled monolayers, Nature material, 9 (2010).

[30] C.A. Schoenbaum, D.K. Schwartz, J.W. Medlin, Controlling surface crowding on a Pd catalyst with thiolate self-assembled monolayers, Journal of Catalysis, 303 (2013) 92-99.

[31] S.H. Pang, C.A. Schoenbaum, D.K. Schwartz, J.W. Medlin, Directing reaction pathways by catalyst active-site selection using self-assembled monolayers, Nature communications, 4 (2013) 2448.

[32] S.H. Pang, C.A. Schoenbaum, D.K. Schwartz, J.W. Medlin, Effects of Thiol Modifiers on the Kinetics of Furfural Hydrogenation over Pd Catalysts, ACS Catalysis, 4 (2014) 3123-3131.

[33] K.R. Kahsar, D.K. Schwartz, J.W. Medlin, Liquid- and vapor-phase hydrogenation of 1-epoxy-3-butene using self-assembled monolayer coated palladium and platinum catalysts, Applied Catalysis A: General, 445-446 (2012) 
102-106.

[34] M. Makosch, W.-I. Lin, V. Bumbálek, J. Sá, J.W. Medlin, K. Hungerbühler, J.A. van Bokhoven, Organic Thiol Modified Pt/TiO2Catalysts to Control Chemoselective Hydrogenation of Substituted Nitroarenes, ACS Catalysis, 2 (2012) 2079-2081.

[35] K.R. Kahsar, D.K. Schwartz, J.W. Medlin, Selective Hydrogenation of Polyunsaturated Fatty Acids Using Alkanethiol Self-Assembled Monolayer-Coated Pd/Al203Catalysts, ACS Catalysis, (2013) 2041-2044.

[36] K.R. Kahsar, D.K. Schwartz, J.W. Medlin, Control of metal catalyst selectivity through specific noncovalent molecular interactions, J Am Chem Soc, 136 (2014) 520-526.

[37] C.-H. Lien, J.W. Medlin, Promotion of Activity and Selectivity by Alkanethiol Monolayers for Pd-Catalyzed Benzyl Alcohol Hydrodeoxygenation, The Journal of Physical Chemistry C, 118 (2014) 23783-23789.

[38] S.-i. Imabayashi, N. Gon, T. Sasaki, D. Hobara, T. Kakiuchi, Effect of Nanometer-Scale Phase Separation on Wetting of Binary Self-Assembled Thiol Monolayers on Au(111), Langmuir : the ACS journal of surfaces and colloids, 1998 (1998) 2348-2351.

[39] A. Stewart, S. Zheng, M.R. McCourt, S.E.J. Bell, Controlling Assembly of Mixed Thiol Monolayers on Silver Nanoparticles to Tune Their Surface Properties, ACS NANO, 6 (2012) 3718-3726.

[40] M. Moreno, F.J. Ibanez, J.B. Jasinski, F.P. Zamborini, Hydrogen reactivity of palladium nanoparticles coated with mixed monolayers of alkyl thiols and alkyl amines for sensing and catalysis applications, J Am Chem Soc, 133 (2011) 4389-4397.

[41] R.G. Nuzzo, L.H. Dubois, D.L. Allara, Fundamental Studies of Microscopic Wetting on Organic Surfaces. 1. Formation and Structural Characterization of a Self-Consistent Series of Polyfunctional Organic Monolayers Journal of The American Chemical Society, 112 (1990) 558-569.

[42] B.W. Gregory, R.A. Dluhy, L.A. Bottomley, Structural characterization and nanometer-scale domain formation in a model phospholipid bilayer as determined by infrared spectroscopy and scanning tunneling microscopy, J. Phys. Chem., 98 (1994) 1010-1021.

[43] T.J. Mullen, A.A. Dameron, H.M. Saavedra, M.E. Williams, P.S. Weiss, Dynamics of Solution Displacement in 1-Adamantanethiolate Self-Assembled Monolayers, J. 
Phys. Chem. C, 111 (2007) 6740-6746.

[44] R.A. MacPhail, H.L. Straws, R.G. Snyder, C-H Stretching Modes and the Structure of n-Alkyl Chains. 2. Long, All-Trans Chains, J. Phys. Chem., 88 (1984) 334-341.

[45] A.A. Dameron, L.F. Charles, P.S. Weiss, Structures and Displacement of 1-Adamantanethiol Self-Assembled Monolayers on Au\{111\}, Journal of The American Chemical Society, 127 (2005) 8697-9704.

[46] N. Camillone, C.E.D. Chidsey, G.-y. Liu, T.M. Putvinski, G. Scoles, Surface structure and thermal motion of n-alkane thiols self-assembled on $\mathrm{Au}(111)$ studied by low energy helium diffraction, The Journal of Chemical Physics, 94 (1991) 8493.

[47] J.C. Love, D.B. Wolfe, R. Haasch, M.L. Chabinyc, K.E. Paul, G.M. Whitesides, R.G. Nuzzo, Formation and Structure of Self-Assembled Monolayers of Alkanethiolates on Palladium, Journal of The American Chemical Society, 125 (2003) 2597-2609.

[48] W.K. Kuhn, J. Szanyi, D.W. Goodman, CO adsorption on Pd(111): the effects of temperature and pressure, Surface Science Letters, 274 (1992) 611-618.

[49] J. Evans, B.E. Hayden, G. Lu, The adsorption of carbon monoxide on TiO2(110) supported palladium, Surface Science, 360 (1996) 61-73.

[50] L.-L. Sheu, Z. Karpinksi, W.M.H. Sachtler, Effects of Palladium Particle Size and Palladium Silicide Formation on Fourier Transform Infrared Spectra of CO Adsorbed on Pd/SiO, Catalysts, J. Phys. Chem., 93 (1989) 4890-4894.

[51] T. Lear, R. Marshall, J.A. Lopez-Sanchez, S.D. Jackson, T.M. Klapotke, M. Baumer, G. Rupprechter, H.J. Freund, D. Lennon, The application of infrared spectroscopy to probe the surface morphology of alumina-supported palladium catalysts, J Chem Phys, 123 (2005) 174706.

[52] B.L. Mojet, S.D. Ebbesen, L. Lefferts, Light at the interface: the potential of attenuated total reflection infrared spectroscopy for understanding heterogeneous catalysis in water, Chemical Society reviews, 39 (2010) 4643-4655.

[53] A.R. Corpuz, S.H. Pang, C.A. Schoenbaum, J.W. Medlin, Hydrogen exposure effects on $\mathrm{Pt} / \mathrm{Al}(2) \mathrm{O}(3)$ catalysts coated with thiolate monolayers, Langmuir : the ACS journal of surfaces and colloids, 30 (2014) 14104-14110.

[54] S. Chen, L. Li, C.L. Boozer, S. Jiang, Controlled Chemical and Structural Properties of Mixed Self-Assembled Monolayers of Alkanethiols on Au(111), 
Langmuir : the ACS journal of surfaces and colloids, 16 (2000) 9287-9293.

[55] J.P. Folkers, P.E. Laibinis, G.M. Whitesides, Self-Assembled Monolayers of Alkanethiols on Gold- Comparisons of Monolayers Containing Mixtures of Short- and Long-chain Constituents with $\mathrm{CH} 3$ and $\mathrm{CHzOH}$ Terminal Groups, Langmuir : the ACS journal of surfaces and colloids, 8 (1992) 1330-1341.

[56] A.A. Dameron, T.J. Mullen, R.W. Hengstebeck, H.M. Saavedra, P.S. Weiss, Origins of Displacement in 1-Adamantanethiolate Self-Assembled Monolayers, J. Phys. Chem. C, 111 (2007) 6747-6752.

[57] H.M. Saavedra, C.M. Barbu, A.A. Dameron, T.J. Mullen, V.H. Crespi, P.S. Weiss, 1-Adamantanethiolate Monolayer Displacement Kinetics Follow a Universal Form, Journal of The American Chemical Society, 129 (2007) 10741-10746. 


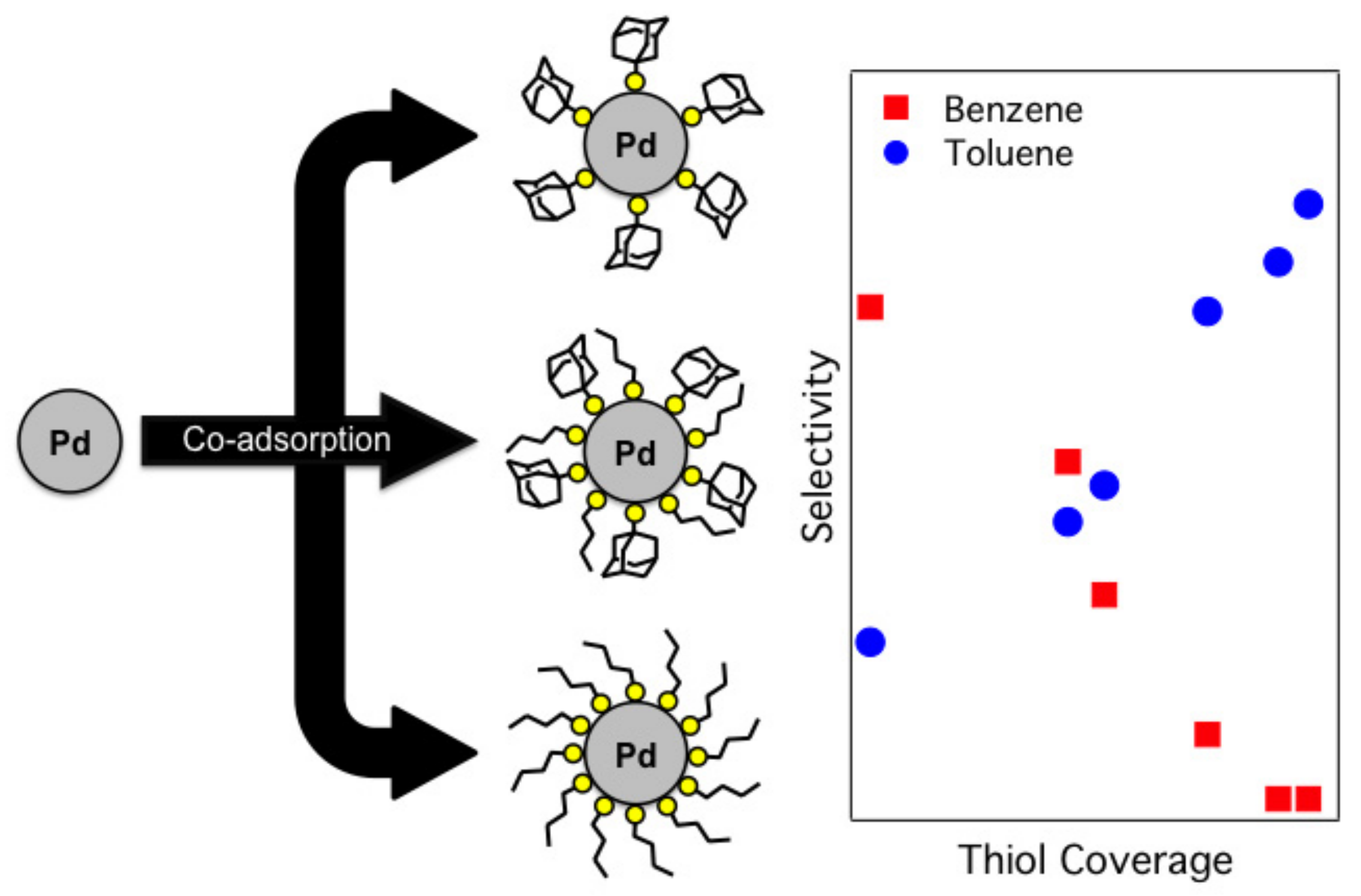

